\title{
Striatal Responses to Partial Dopaminergic Lesion: Evidence for Compensatory Sprouting
}

\author{
David D. Song ${ }^{2}$ and Suzanne N. Haber ${ }^{1,2}$ \\ ${ }^{1}$ Department of Neurobiology and Anatomy, and 2Department of Neurology, University of Rochester School of Medicine, \\ Rochester, New York 14642
}

Dopaminergic lesions result in the acute loss of striatal dopamine content, the loss of tyrosine hydroxylase-immunoreactive fibers, upregulation of preproenkephalin mRNA expression, and compensatory changes in the synthesis and metabolism of dopamine. Despite the severe loss of fine tyrosine hydroxylaseimmunoreactive fibers, larger fibers persist. We found that some tyrosine hydroxylase fiber types increase their branching and become thicker after partial lesion. To determine whether the remaining tyrosine hydroxylase fibers were degenerative or part of a compensatory response, we morphologically characterized striatal tyrosine hydroxylase fibers and compared them to silver-stained degenerative structures. Branched and large tyrosine hydroxylase fiber types were nondegenerative. Furthermore, normal preproenkephalin mRNA expression was maintained despite severe overall loss of tyrosine hydroxylase fibers in striatal regions with abundant branching, whereas preproenkephalin mRNA expression increased in severely depleted regions that lacked branched fibers, indicating that branching or sprouting was involved in the compensation for dopamine depletion and the maintenance of normal preproenkephalin expression. In support of compensatory sprouting by tyrosine hydroxylase fibers, mRNA for growth associated protein-43 was upregulated in dopaminergic midbrain cells. We conclude that an important compensatory response to partial dopaminergic depletion is the formation of new branches or sprouting.

Key words: MPTP; dopamine; plasticity; enkephalin; GAP-43; striatum; substantia nigra
There are a variety of neurochemical and morphological changes that occur in the striatum as a consequence of lesioning of the mesostriatal dopamine (DA) system. These changes reflect both the acute loss of DA innervation and compensations for that loss. Acute changes include the loss of tyrosine hydroxylase (TH)immunoreactive fibers and terminals, the appearance of axonal and terminal degeneration, loss of striatal DA content, and an increase in the expression of preproenkephalin (PPE) mRNA (Onn et al., 1986; Hess, 1989; Boatell et al., 1992; Albanese et al., 1993; Asselin et al., 1994). Compensatory responses include increased synthesis of $\mathrm{TH}$, increased DA release and turnover, and decreased DA uptake, leading to maintenance of normal or near normal levels of extracellular dopamine (Zhang et al., 1988; Zigmond et al., 1989, 1990; Abercrombie et al., 1990; Robinson et al., 1990; Robinson et al., 1994).

The neurotoxin 1-methyl-4-phenyl-1,2,3,6-tetrahydropyridine (MPTP) has been extensively used to selectively lesion the mesostriatal DA system in primates (Langston et al., 1984; Gerlach and Riederer, 1996). A marked decrease in the dense network of terminals and thin TH fibers occurs after MPTP lesions; however, large diameter fibers persist. The prominence of these residual large fibers have been interpreted to be a result of the loss of background TH immunoreactivity (Hess, 1989; Parent and Lavoie, 1993). However, preliminary evidence from our labora-

\footnotetext{
Received Dec. 23, 1999; revised March 27, 2000; accepted April 18, 2000.

This work was supported by National Institutes of Health Grant NS22511 to S.N.H. and the Lucille P. Markey Charitable Trust. We thank Dr. Robert C. Switzer III for his assistance in performing the silver staining and April Whitbeck and Evelyn Galban for their excellent technical assistance.

Correspondence should be addressed to S. N. Haber, Department of Neurobiology and Anatomy, University of Rochester School of Medicine, 601 Elmwood Avenue, Rochester, NY 14642. E-mail: Suzanne_Haber@urmc.rochester.edu. Copyright (C) 2000 Society for Neuroscience $0270-6474 / 00 / 205102-\bullet \$ 15.00 / 0$
}

tory indicated a change in the density and morphology of largediameter fibers in MPTP-lesioned animals (Song et al., 1999). These changes raised the issue of whether growth and sprouting could be an additional compensatory mechanism for DA loss. Previous studies have suggested that sprouting from remaining mesolimbic DA fibers can occur (Onn et al., 1986; Hansen et al., 1995). Consistent with this possibility, the substantia nigra neurons contain relatively high levels of growth-associated protein 43 (GAP-43) (Bendotti et al., 1991). This protein, which is highly expressed in the brain during development, is also inducible in the adult brain during recovery after injury (Dani et al., 1991; Benowitz and Routtenberg, 1997; Anderson et al., 1998). If indeed new sprouts or branches are formed by remaining DA mesostriatal fibers, then acute striatal responses to DA depletion might be normalized by this sprouting or growth.

One of the most consistent striatal responses to decreased dopamine levels is the upregulation of PPE mRNA (Tang et al., 1983; Normand et al., 1988; Augood et al., 1989; Gerfen et al., 1991). This is heterogeneous in MPTP-lesioned primates (Asselin et al., 1994; Parent et al., 1996). Because the striatal expression of PPE mRNA is tightly linked to DA transmission (Mocchetti et al., 1987; Normand et al., 1988; Li et al., 1990; Kowalski and Giraud, 1993; Nisenbaum et al., 1994), striatal change or lack of change in PPE mRNA expression may reflect the extent of extracellular DA normalization. This normalization may be attributable to both neurochemical or sprouting responses to DA depletion.

To address the progression of changes in the striatum after a partial DA lesion, we studied the distribution and morphology of large-diameter fibers after mild, moderate, and severe DA lesions to determine: (1) their relationship to the decrease in dopaminergic thin fiber networks; (2) whether they represented degen- 

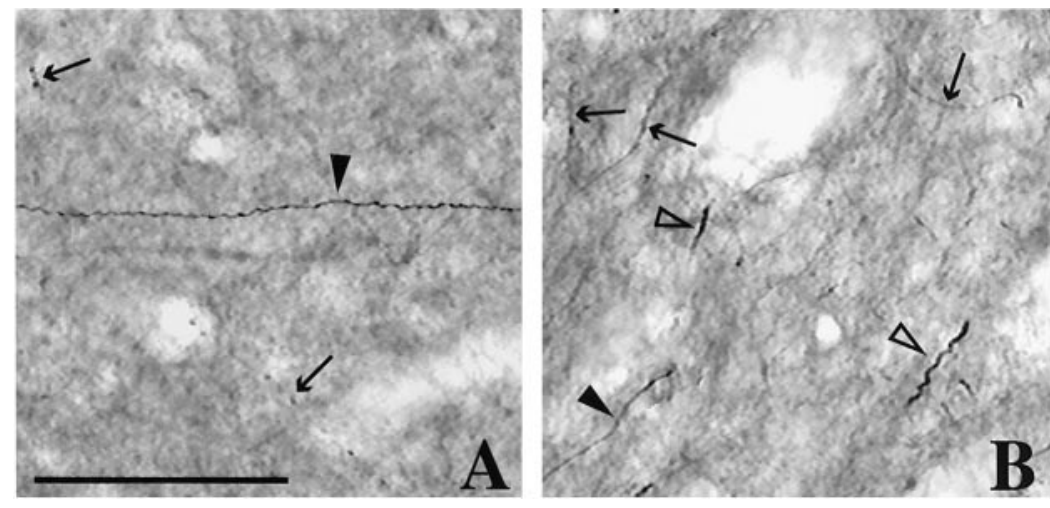

Figure 1. Normal TH-immunoreactive fiber types. $A$, Dorsal striatum (dorsolateral putamen). $B$, Ventral striatum (nucleus accumbens). Arrows, Type II TH fibers. Closed arrowheads, Type III TH fibers. Open arrowheads, Type IV TH fibers. Type I TH fibers compose the fine background immunoreactivity. Scale bar, $50 \mu \mathrm{m}$. erating or nondegenerating fibers; (3) their relationship to the expression of PPE mRNA, and (4) their expression of GAP-43 mRNA in the midbrain. We classified TH-immunoreactive fibers in the striatum into morphological subtypes. We evaluated degenerative elements using the aminocupric acid silver stain (De Olmos et al., 1994) and used combined staining for TH immunoreactivity and neurodegeneration to determine whether the large-diameter fibers were undergoing degeneration. Also, we examined the relationship between the density and morphology of thick-diameter, TH-positive fibers, with distribution of PPE mRNA upregulation. Finally, we compared the expression levels of GAP-43 in the midbrain between controls and MPTP-treated animals.

\section{MATERIALS AND METHODS}

MPTP treatment and behavioral assessment. Seven old world monkeys (Macaca nemistrina) were used for this study. Food and water were available ad libitum. Animal procedures were conducted in accordance with the Guide for the Care and Use of Laboratory Animals as adopted by the National Institutes of Health. Four monkeys were treated with 0.15 $\mathrm{mg} / \mathrm{kg}$ of MPTP three times a week, and three served as normal controls. MPTP treatment was terminated within $48 \mathrm{hr}$ of the emergence of bradykinesia, action tremor, stooped posture, or change in gait. One case (total dose $1.05 \mathrm{mg} / \mathrm{kg}$ ) was mildly affected behaviorally with minimal bradykinesia and a small tremor of the left hand. Two cases were moderately affected (total doses of $2.70 \mathrm{mg} / \mathrm{kg}$ and $1.50 \mathrm{mg} / \mathrm{kg}$ ) with moderate bradykinesia, stooped postures, and some difficulties with balance and gait, but were able to independently feed and groom. One case was severely affected (total dose, $1.80 \mathrm{mg} / \mathrm{kg}$ ) with frequent akinesia (freezing), very stooped posture, and severe difficulty in moving. This animal required assisted feeding and did not groom.

Histology. Four to five weeks after the last dose of MPTP, monkeys were deeply anesthetized with a lethal dose of pentobarbital and killed by perfusion through the heart with saline followed by a $4 \%$ paraformaldehyde solution in $0.1 \mathrm{M}$ phosphate buffer, $\mathrm{pH}$ 7.4. The brains were removed and cryoprotected in increasing gradients of sucrose $(10,20$, and finally $30 \%$ ). Serial sections of $50 \mu \mathrm{m}$ were cut on a freezing microtome and processed for immunocytochemistry for $\mathrm{TH}$ and in situ hybridization for either PPE or GAP-43 mRNA.

Tissue processed for $\mathrm{TH}$ immunocytochemistry was incubated with antisera to TH $(1: 20,000$; Eugene Tech) in $0.1 \mathrm{M}$ phosphate buffer with $0.3 \%$ Triton X-100 and 10\% normal goat serum (PBS-T-NGS; Incstar, Stillwater, $\mathrm{MN}$ ) for four nights at $4^{\circ} \mathrm{C}$ and further processed using the avidin-biotin method (rabbit Elite Vectastain ABC kit; Vector Laboratories, Burlingame, CA). Sections were rinsed first in PBS then in Tris buffer $(0.05 \mathrm{M}, \mathrm{pH} 7.6)$ and preincubated in a filtered $0.05 \% 3,3^{\prime}$ diaminobenzidine tetrahydrochloride solution in Tris buffer for $10 \mathrm{~min}$, before adding $0.01 \% \mathrm{H}_{2} \mathrm{O}_{2}$.

In situ hybridization. The PPE probe was a 48-mer complementary to the human PPE mRNA sequence encoding amino acids 130-145 (Comb et al., 1982). The GAP-43 probe was a 40-mer complementary to the human GAP-43 mRNA sequence (GenBank M25667) encoded by bases $158-197$. Five picomoles of oligonucleotide were radiolabeled in a $20 \mu \mathrm{l}$ reaction using 50 units of terminal deoxynucleotidyl transferase (TdT; Boehringer Mannheim, Indianapolis, IN) and 50 picomoles of deoxya- denosine $5^{\prime} \alpha$-thio $\left[{ }^{35} \mathrm{~S}\right]$ triphosphate $\left(\left[{ }^{35} \mathrm{~S}\right] \mathrm{dATP} ;>1250 \mathrm{Ci} / \mathrm{mmol}\right.$; New England Nuclear, Boston, MA) in a buffer containing $200 \mathrm{~mm}$ potassium cacodylate, $25 \mathrm{~mm}$ Tris- $\mathrm{HCl}, \mathrm{pH} 6.6$ at $25^{\circ} \mathrm{C}, 0.25 \mathrm{mg} / \mathrm{ml}$ bovine serum albumin, and 1.5 or $5.0 \mathrm{~mm}$ cobalt chloride. Unincorporated radiolabel was removed by ethanol precipitation in a $1 \mathrm{mg} / \mathrm{ml}$ glycogen and $0.4 \mathrm{M}$ lithium chloride solution. Pellets were rinsed in $70 \%$ ethanol, dried, redissolved in $10 \mathrm{~mm}$ Tris-HCl, $1 \mathrm{~mm}$ EDTA, pH 7.6 (TE), and $50 \mathrm{~mm}$ dithiothreitol (DTT; Sigma, St. Louis, MO), and stored at $-20^{\circ} \mathrm{C}$.

Tissue sections were processed for in situ hybridization free-floating as previously described (Lu and Haber, 1992). Sections were rinsed two times for 15 min each in PBS before being rinsed briefly in a buffer containing $0.1 \mathrm{M}$ triethanolamine, $0.9 \%$ sodium chloride, $\mathrm{pH} 8.0$ (TEA$\mathrm{NaCl}$ ), and then incubated for $10 \mathrm{~min}$ in $0.25 \%$ acetic anhydride in TEA-NaCl and then transferred to $2 \times \mathrm{SSC}(1 \times \mathrm{SSC}=0.15 \mathrm{M}$ sodium chloride and $0.015 \mathrm{M}$ sodium citrate, $\mathrm{pH} 7.0$ ) and rinsed two times for 5 min. The final prehybridization treatment was a 10 min rinse in $50 \%$ formamide (Sigma), $4 \times$ SSC.

The ${ }^{35}$ S-labeled probes were diluted $\left(0.01-0.30 \times 10^{7} \mathrm{cpm} / \mathrm{ml}\right.$ hybridization solution) in a hybridization buffer containing $4 \times \mathrm{SSC}, 50 \%$ formamide, $10 \times$ Denhardt's solution, $100 \mu \mathrm{g} / \mathrm{ml}$ denatured salmon sperm DNA (Sigma), $100 \mu \mathrm{g} / \mathrm{ml}$ polyadenylic acid (Sigma), $250 \mu \mathrm{g} / \mathrm{ml}$ yeast tRNA (Boehringer Mannheim), $5 \mu \mathrm{g} / \mathrm{ml}$ polydeoxyadenylic acid (Sigma), $50 \mathrm{~mm}$ DTT, and 10\% dextran sulfate (5 Prime-3 Prime, Inc., Boulder, CO). Sections were transferred into hybridization solution in a $14 \mathrm{ml}$ sterile culture tube (one section per milliliter or two sections per 3 $\mathrm{ml}$ of hybridization solution), and incubated gently rocking overnight at $37^{\circ} \mathrm{C}$. After hybridization, sections were transferred into nets in dishes and sequentially rinsed at room temperature (two times for $10 \mathrm{~min}$ each) in $2 \times$ SSC, $1 \times$ SSC, and $0.5 \times$ SSC. Finally, sections were rinsed in $0.5 \times$ $\mathrm{SSC}$ at $50-60^{\circ} \mathrm{C}$ ), four times for $30 \mathrm{~min}$, rinsed briefly in room temperature $0.1 \mathrm{~m}$ phosphate buffer, and then mounted on gelatin-coated slides.

The slides were apposed to Hyperfilm B-max films (Amersham, Arlington Heights, IL) for 3-7 d, then dehydrated and defatted through increasing concentrations of $\mathrm{ETOH}$, into xylene for two times overnight, rehydrated, dried on a slide warmer, and dipped into NTB-2 photographic emulsion (Eastman Kodak, Rochester, NY) that has been diluted $1: 2$ with $20 \%$ glycerin, exposed for $3-5$ weeks at $-20^{\circ} \mathrm{C}$, developed in D-19 developer (Kodak), fixed, rinsed with water, counterstained with cresyl violet, coverslipped with Permount (Fisher Scientific, Springfield, NJ), and examined microscopically under dark-field and bright-field illumination. The sense probe is substituted for the antisense probe to confirm specificity of hybridization.

Aminocupric acid silver staining. Four sections from each MPTPtreated and control animal were processed by Neuroscience Associates (Knoxville, TN) with the assistance of Dr. Robert C. Switzer III for degeneration using the aminocupric acid silver stain originally described by De Olmos et al. (1994). An additional five sections from each animal were also stained for both TH immunoreactivity and silver impregnation. Routine processing for $\mathrm{TH}$ was completed first, followed by routine aminocupric acid silver staining. Sections from control animals were simultaneously processed with sections from treated animals. Analysis of the distribution and morphology of silver-impregnated structures was based on sections processed only for degeneration because normal control did not show degenerating fibers.

Fiber types. Images of TH-immunoreactive fibers and silverimpregnated structures were digitally captured at $40 \times$ magnification and measured using Openlab software (Improvision). TH-immunoreactive fibers in the striatum of normal controls were classified by morphology 

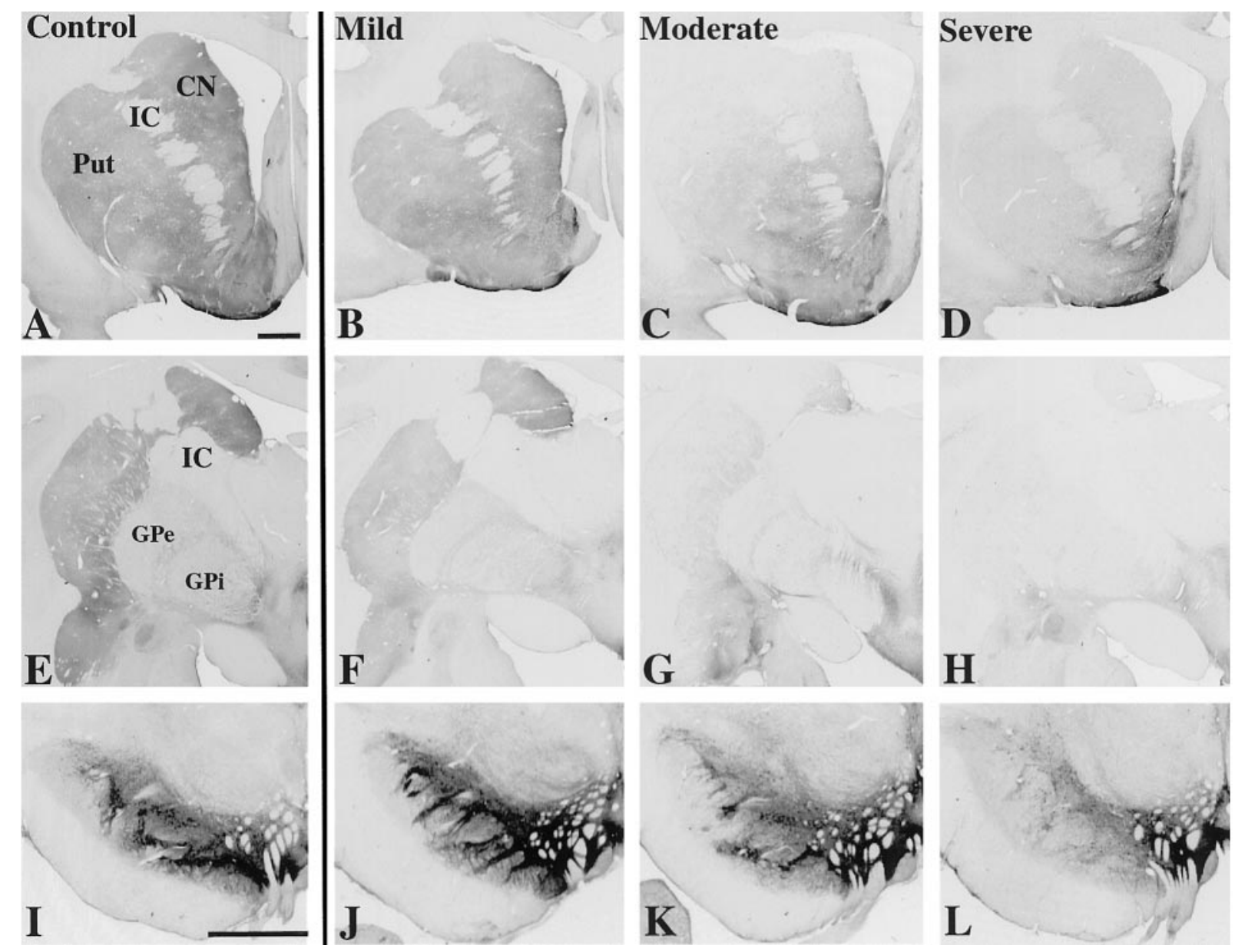

Figure 2. Distribution of TH immunoreactivity from control $(A, E, I)$ and MPTP-treated animals $(B-D, F-H, J-L)$. $A-D$, Rostral striatum. $E-H$, Caudal striatum. $I-L$, Midbrain. $C N$, Caudate nucleus; $G P i$, globus pallidus interna; $G P e$, globus pallidus externa; $I C$, internal capsule; $P u t$, putamen. Scale bar, $2 \mathrm{~mm}$.

and thickness (Fig. 1). There was some overlap in the range of diameters for each fiber type category; however, morphological differences distinguished the fiber types. Type I fibers were $<0.25 \mu \mathrm{m}$ in diameter. These fibers were very fine and composed the fine mesh of TH immunoreactivity found throughout the striatum. Type II fibers (arrows) were $0.25-$ $0.80 \mu \mathrm{m}$ in diameter (mean, $0.50 \mu \mathrm{m} ; n=387$ ). These fibers had varicosities along their length, were predominantly nonbranching, and often appeared wavy. Of the measured type II fibers that did branch, there were never more than two branches per fiber. Type III fibers (closed arrowheads) were $0.45-1.25 \mu \mathrm{m}$ in diameter (mean, $0.77 \mu \mathrm{m} ; n=$ 471). Unlike type II fibers, they were smooth, straight, had no varicosities along their length, and were always nonbranching. Type IV fibers (open arrowheads) were $0.55-2.1 \mu \mathrm{m}$ in diameter (mean, $1.11 \mu \mathrm{m} ; n=156$ ). Although some were similar in thickness to type III fibers, they were kinked or twisted, had particularly intense and granulated TH immunoreactivity, and were often much thicker than type III fibers. The branching of these fibers was rare. In MPTP-treated animals, silverimpregnated degenerating structures were also classified morphologically using the same criteria for $\mathrm{TH}$-immunoreactive fibers described above (see Results for details). Silver impregnated fiber-like structures were called type II-like, type III-like, or type IV-like. Type IV-like structures were further subdivided two distinct morphological subgroups, 4A and 4B (see Results).

\section{RESULTS}

\section{Tyrosine hydroxylase immunoreactivity}

In control animals, there was dense $\mathrm{TH}$ immunoreactivity throughout the striatum (Fig. $2 A, E$ ). The intensity of staining for $\mathrm{TH}$ immunoreactivity was heterogeneous with a patchy and un- even pattern (Fig. $2 A, E$ ). Type I fibers were the most abundant fiber type throughout the striatum (Figs. 1, $3 A$ ). Type II fibers were also abundant throughout the striatum, but more so in the ventral striatum than in the dorsal striatum (Figs. 1, 3A, arrows). The thickness and varicosities of type II fibers clearly distinguished these fibers from type I fibers. Type III fibers (Figs. 1, 3A, closed arrowheads) were much less abundant throughout the striatum than type I or II. Whereas these fibers were found scattered throughout the striatum, they were more abundant dorsally. Type IV fibers were found infrequently, were particularly thick, irregular, and relatively short (Fig. 1B, open arrowheads). These fibers were found primarily in the ventral striatum.

Each MPTP-treated case was classified as mild, moderate, or severe based on severity of Parkinsonian signs (see Materials and Methods). Figure $2 B-D$ and $F-H$ shows the extent of overall loss of TH immunoreactivity in the MPTP-treated animals arranged by severity. In the mild case, there was robust $\mathrm{TH}$ immunoreactivity throughout the striatum at rostral and caudal levels (Fig. $2 B, F)$. There was only mild loss of $\mathrm{TH}$ immunoreactivity in the dorsolateral striatum. In moderate cases, there was a dramatic decrease in $\mathrm{TH}$ immunoreactivity in the dorsolateral striatum, including most of the putamen and much of the caudate nucleus (Fig. 2C, $G$ ). This loss was most extensive caudally. TH immunoreactivity in the ventral striatum was spared. In the severe case, 

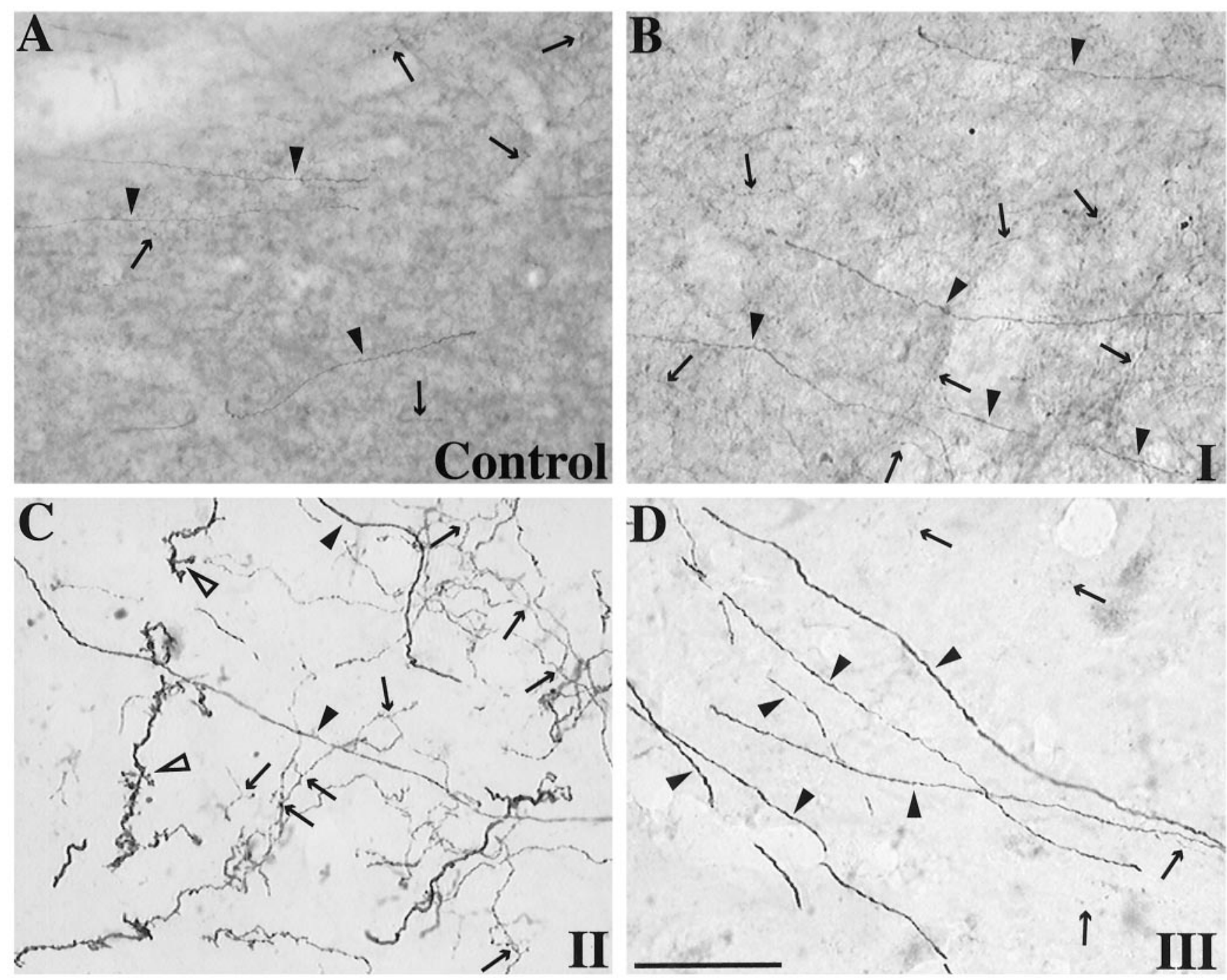

Figure 3. Stages of TH-immunoreactive fiber loss in the dorsolateral striatum. $A$, Control. $B$, Stage I from mild case. $C$, Stage II from a moderate case. $D$, Stage III from severe case. Arrows, Type II fibers. Closed arrowheads, Type III fibers. Open arrowheads, Type IV fibers. Scale bar, $50 \mu \mathrm{m}$.

massive depletion of $\mathrm{TH}$ immunoreactivity extended throughout the entire dorsal striatum and into the ventrolateral aspects of the nucleus accumbens (Fig. 2D,H). The medial nucleus accumbens retained relatively high amounts of $\mathrm{TH}$ immunoreactivity.

\section{Stages of TH fiber loss}

Changes in the distribution and morphology of TH fiber types were classified into stages by severity (Table 1), as follows: stage I (Fig. 3B) was defined by decreased density of type I fibers and sparing of type II, III, and IV fibers. Stage II (Fig. 3C) was defined by a total loss of type I fibers, decrease in density of type II fibers, increased density of branched type II and IV fibers, and sparing of type III fibers. Stage III (Fig. $3 D$ ) was defined by a total loss of type I fibers, near total loss of type II and branched fibers, and sparing of unbranched type III and IV fibers. The transitions from one stage to the next were distinct (Fig. 4), dividing the striatum into regions based on stages of TH fiber loss. Figure 5 demonstrates the dorsolateral to ventromedial flow in the stages of TH fiber loss with increasing severity of lesion. The region of stage I changes was located in the dorsolateral striatum of the mild case (Fig. 5A), centrally in the striatum of the moderate cases (Fig. $5 B$ ), and ventrally in the severe case (Fig. $5 C$ ). The

\begin{tabular}{lllll}
\hline \multicolumn{5}{l}{ Table 1. Stages of striatal TH fiber loss } \\
& $\begin{array}{l}\text { Type I } \\
\text { fibers }\end{array}$ & $\begin{array}{l}\text { Type II } \\
\text { fibers }\end{array}$ & $\begin{array}{l}\text { Type III } \\
\text { fibers }\end{array}$ & $\begin{array}{l}\text { Type IV } \\
\text { fibers }\end{array}$ \\
\hline Stage I & Decreased & No change & No change & No change \\
Stage II & Total loss & $\begin{array}{l}\text { Decreased density } \\
\text { Increased branching }\end{array}$ & No change & $\begin{array}{l}\text { Increased } \\
\text { branching }\end{array}$ \\
Stage III & Total loss & $\begin{array}{l}\text { Near total loss } \\
\text { Lost branching }\end{array}$ & No change & Lost branching \\
& & Lost &
\end{tabular}

Stages of striatal TH fiber loss after partial dopaminergic lesioning. Listed are the changes in the TH-immunoreactive fiber types for each stage. Note stage II is characterized by increased branching of type II and IV fibers.

region of stage II changes shifted from the middle dorsal striatum in the moderately affected cases (Fig. $5 B$ ) to the ventromedial rim of the dorsal striatum in the severely affected case (Fig. $5 C$ ). The lower boundary of stage III changes also moved ventromedially. In the moderate cases, stage III changes occurred in the dorsolateral third of the dorsal striatum (Fig. $5 B$ ). In the severe case, approximately half of the dorsal striatum demonstrated stage III changes (Fig. 5C). The mildly affected case did not show stage II or stage III changes. 


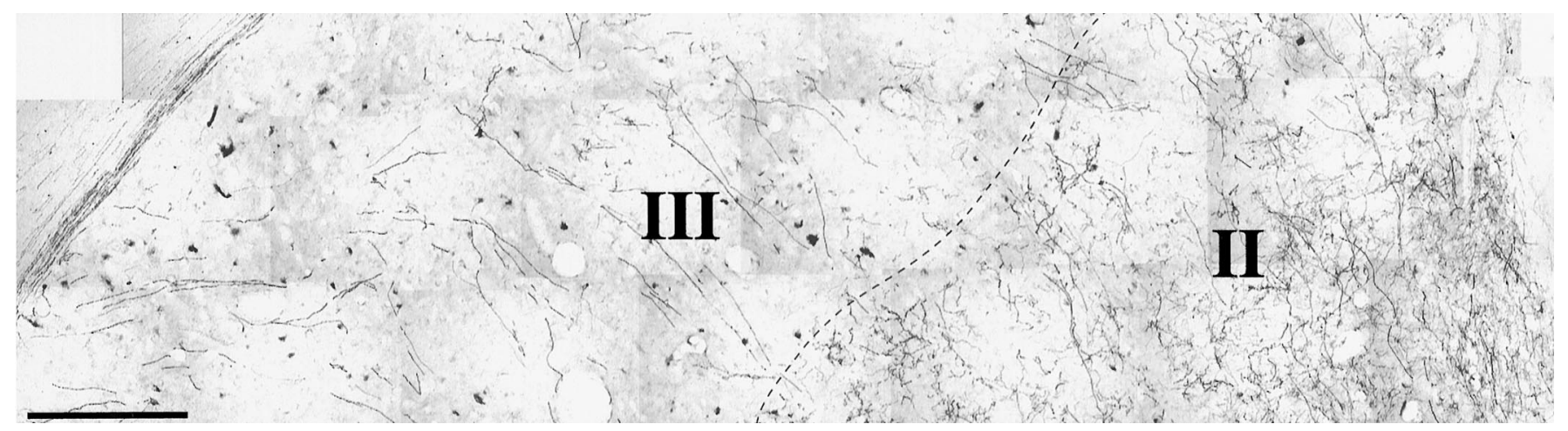

Figure 4. Stage II to stage III transition (dashed line) in the dorsolateral putamen after MPTP treatment. In stage II (ventromedial, right), there is abundant branching of remaining TH-immunoreactive fibers. In stage III (dorsolateral, left), there is near complete absence of branching. Scattered dark amorphous staining is endogenous peroxidase activity from activated phagocytes. Scale bar, $1 \mathrm{~mm}$.
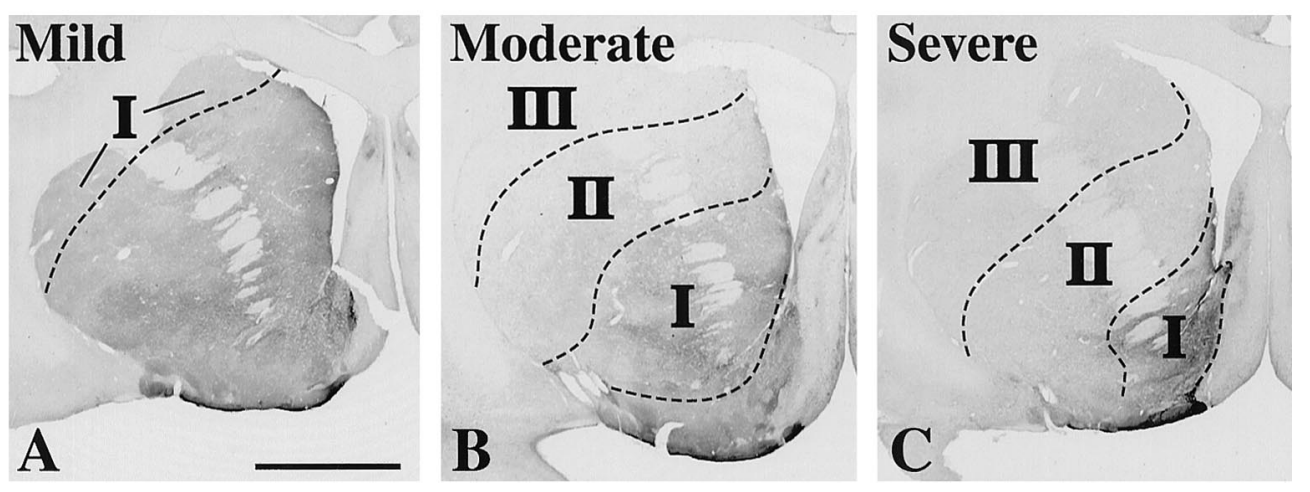

Figure 5. Distribution of stages in striatal TH fiber loss (stages I, II, and III) after different degrees of MPTP lesion. $A$, Mild; $B$, moderate; $C$, severe. Scale bar, $5 \mathrm{~mm}$.

In stage II regions, type II fibers showed a distinct change in morphology (Fig. 3C, arrows). They were thicker, more convoluted, and highly branched. Infrequently, did any type II fibers show the unbranched and beaded morphology that was typical in controls. Type III and IV fibers were quite abundant and not reduced (Fig. 3C, closed and open arrowheads, respectively). Unlike controls, many of the type IV fibers had multiple distinct branches (Figs. 3C, 6, black arrows and open arrowheads) and "bushy" processes (Fig. 6, open arrows). These bushy processes were morphologically distinct from the dendritic spines identified on TH-immunoreactive striatal spiny neurons. Furthermore, dendritic processes were notably smoother and straighter than type IV TH fibers. In no instance were any of these thickened branching $\mathrm{TH}$ fibers found emanating from an intrinsic $\mathrm{TH}-$ immunoreactive striatal neuron.

\section{Staining for striatal neurodegeneration}

There was little to no deposition of silver in control sections (Fig. $7 A, C)$. There was progressively more silver deposits visible in the striatum with increasing severity of MPTP lesion (Fig. $7 D-F$ ). In the mild case, silver deposits were mostly punctuate or vesicular and rarely were fiber-like in appearance (Figs. $7 D, 8 B$ ). In moderate cases, there was more widespread silver deposition (Figs. $7 E, 8 C)$. Deposition was in the form of fiber-like structures, but there was also widespread punctuate and vesicular deposition. The severely affected case had the greatest amount of striatal silver deposits among the treated animals (Figs. $7 F, 8 D$ ). The overall pattern was similar to the moderate cases, but it was more intense dorsolaterally. In moderately and severely affected cases, the density of degenerative fibers exceeded the density of type III and IV TH-immunoreactive fibers in the dorsolateral striatum. Deposits were unevenly distributed within the striatum with patchy areas of increased deposition (Fig. 7B). The silver deposition could be traced caudally and ventromedially through the globus pallidus to the substantia nigra. Furthermore, many silverimpregnated cells were present in the substantia nigra, pars compacta (SNpc).

There were two general types of silver-impregnated fiber-like structures, type II-like and type IV-like (Fig. 8, white arrows and double arrowheads, respectively). There were no structures that had a type III-like appearance. Type II-like structures were relatively thin (mean diameter, $0.63 \mu \mathrm{m} ; n=315$ ), nonbranching, and beaded (Fig. 8, white arrows). The larger type IV-like structures were all nonbranching and could be further subdivided into two subtypes, 4A and 4B. Type 4A (mean diameter, $0.84 \mu \mathrm{m} ; n=$ 120) had a distinct twisted or "corkscrew" appearance, matching the morphology of a subset of type IV TH fibers. Type 4B were longer, relatively thick, and irregular in thickness (mean diameter, $1.01 \mu \mathrm{m} ; n=162$ ) with a distinctively kinked morphology (Fig. 8, double arrowheads). The Type 4B morphology was found uniquely in the silver-stained sections, but not in striatal sections processed for $\mathrm{TH}$ immunoreactivity alone. The densities of type II-like and type IV-like deposits increased in the dorsal striatum with increasing severity of MPTP-induced lesion.

The vast majority of silver-impregnated fibers were a separate 


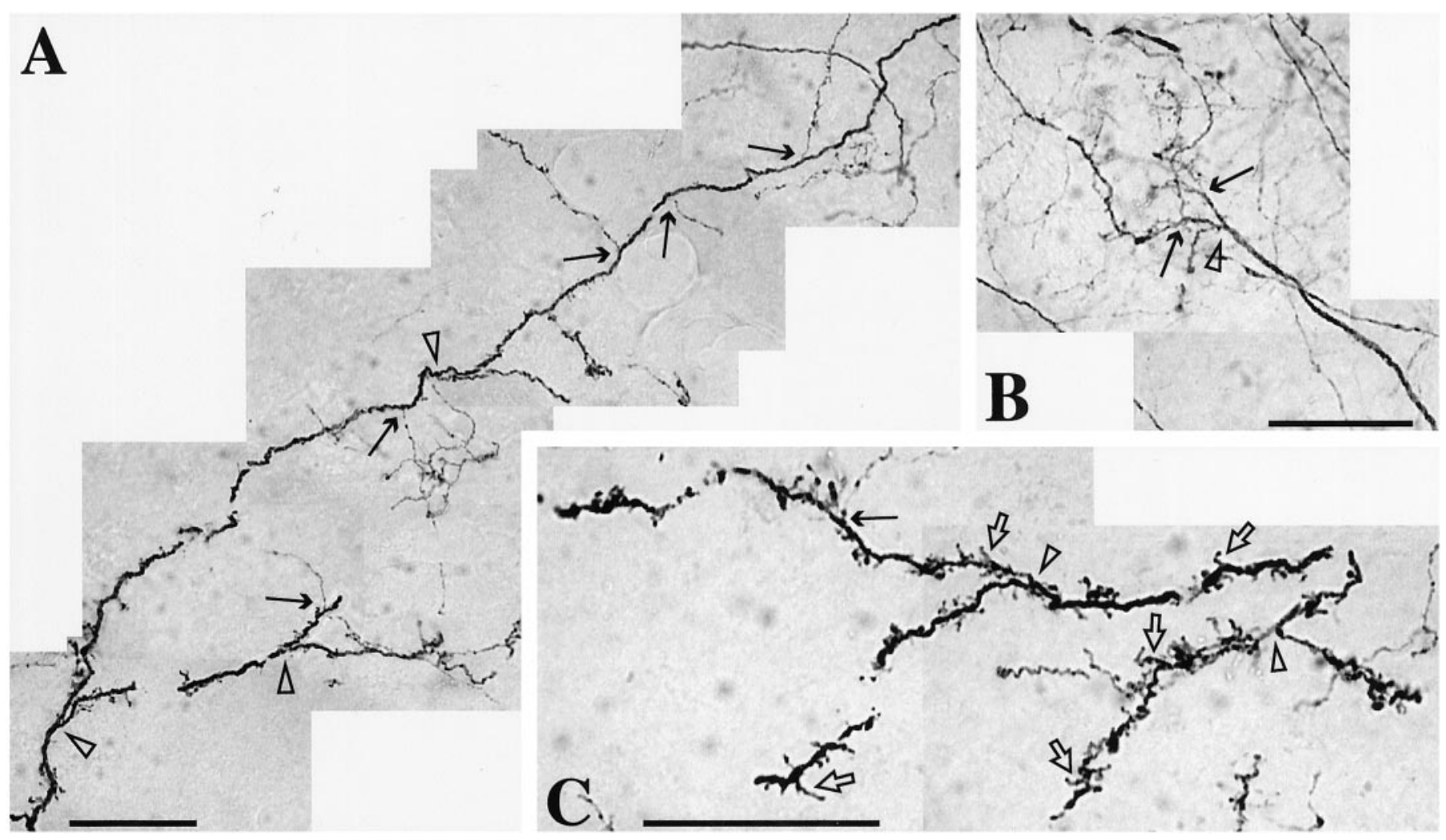

Figure 6. Branched type II and IV TH fibers found in stage II striatal regions after MPTP treatment. $A$, Long type IV TH fiber with multiple branches. $B$, Cluster of fibers branching or "sprouting" from a thicker type IV TH fiber. $C$, Multiple "bushy" processes covering branched fibers in stage II regions. Arrows, Type II fibers. Open arrowheads, Type IV fibers. Open arrows, Bushy processes. Scale bar, $50 \mu \mathrm{m}$.
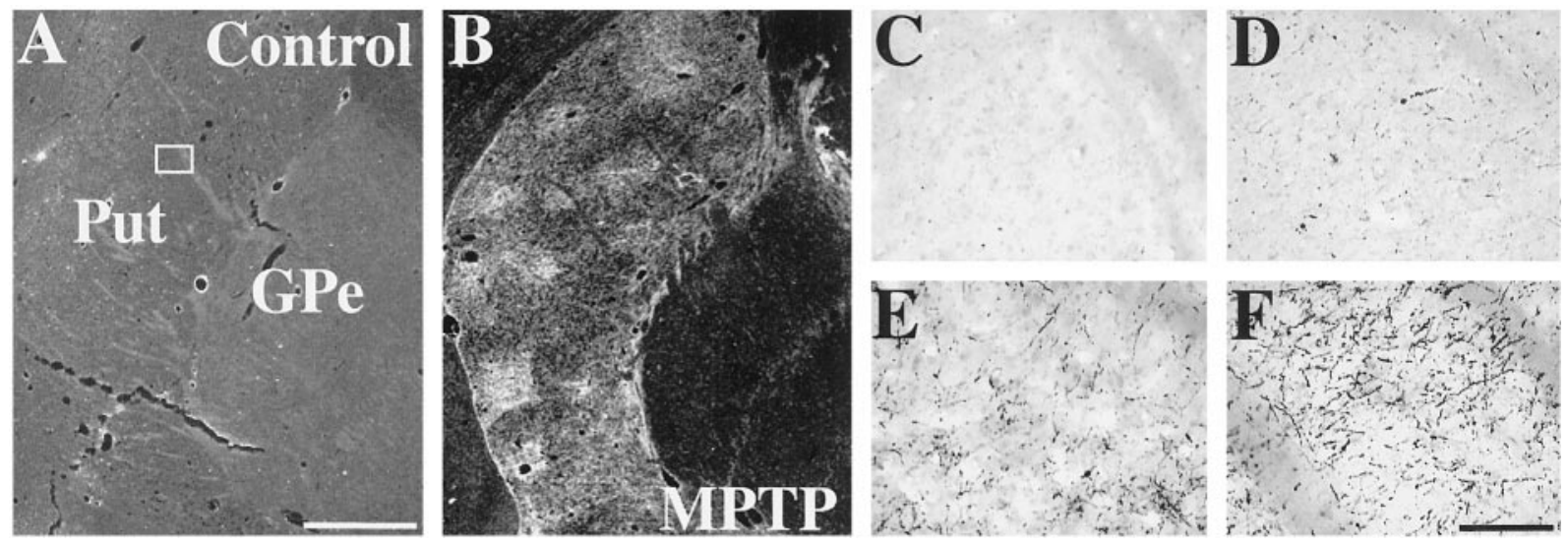

Figure 7. Striatal distribution of degenerative elements identified by aminocupric acid silver staining. $A$, $B$, Dark-field views: $A$, control; $B$, severe MPTP-treated case. $C-F$, Bright-field views corresponding to boxed region in panel $A$ : $C$, control; $D$, mild MPTP; $E$, moderate MPTP; and $F$, severe MPTP. Put, Putamen; GPe, globus pallidus externa. Scale bars: $A, B, 2 \mathrm{~mm} ; C-F, 100 \mu \mathrm{m}$.

population from those stained for TH immunoreactivity (Fig. 8). The long, smooth type III (closed arrowheads), branched type II (black arrows), and branched type IV (open arrowheads) THimmunoreactive fibers contrasted distinctly from the separate shorter, thinner, kinked, and twisted type IV-like silver deposits (white arrowheads). For the most part, the type II-like deposits (white arrows) were also separate populations from the type II TH fibers (black arrows). However, there was some colocalization of TH with silver deposits on beaded nonbranching type II fibers. Colocalization was found more frequently in the moderate cases than in the severe case.

\section{The relationship of PPE mRNA expression to TH fiber types}

In control animals, PPE mRNA expression was highest ventromedially and lowest dorsolaterally (Fig. 9A). The mildly affected case showed no apparent change from controls (Fig. 9B). In the moderate cases, striatal PPE mRNA expression was increased in the dorsolateral striatum, predominantly in the putamen (Fig. $9 C)$. Ventromedial expression remained similar to controls. The most severely affected case also demonstrated a dorsolateral increase in PPE expression similar to the moderate cases, but the 

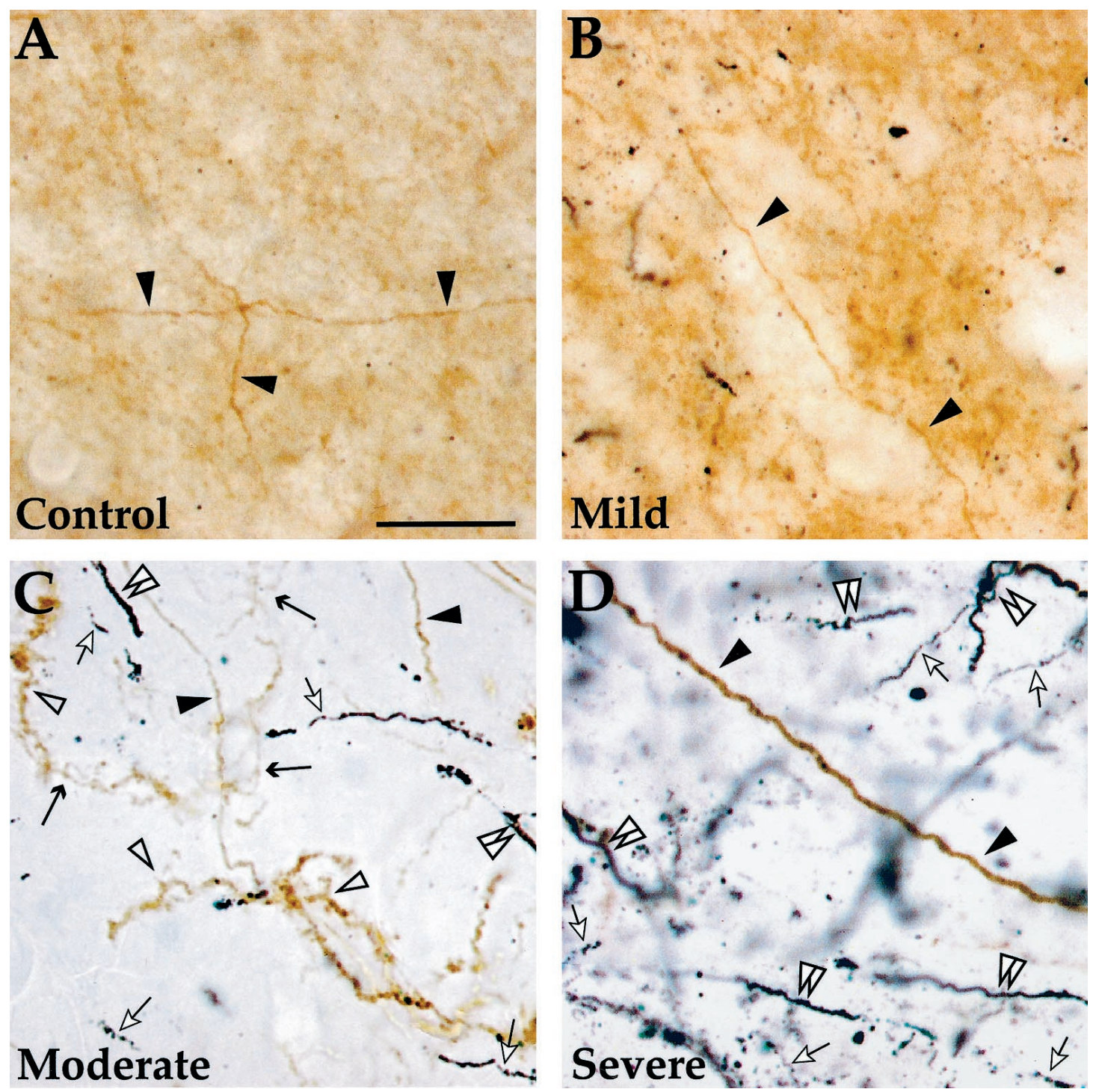

Figure 8. Combined TH immunocytochemistry (brown) and aminocupric acid silver staining (black) in the dorsolateral putamen. $A$, Control. $B-D$, MPTP-treated animals. Note lack of colabeling in MPTP treated cases. Black arrows, Type II TH fibers. Black arrowheads, Type III TH fibers. Open single arrowheads, Type IV TH fibers. White arrows, Type II-like silver deposits. White double arrowheads, Type IV-like silver deposits. Scale bar, 50 um.

region of increase extended more into the central striatum (Fig. $9 D)$. PPE expression in the most ventromedial regions remained at control levels. For each of the moderately and severely affected cases, the region of increased PPE expression was more extensive caudally than rostrally. This pattern of increased PPE mRNA expression was in parallel to the previously described pattern of TH-immunoreactive fiber loss for these same animals. Indeed, analysis of adjacent sections demonstrated that there was a close correspondence of the stage II to stage III transition with the transition of relatively normal to increased PPE mRNA expression (Figs. 10, 11). In other words, regions with stage III changes matched regions having increased PPE mRNA expression, and stage I and II regions matched striatal regions with no apparent change in PPE mRNA expression, despite clear reductions in $\mathrm{TH}$ immunostaining. In the caudate nucleus, the correspondence was not as striking as that seen in the putamen at low magnification. However, at higher magnification, the increases in PPE mRNA were distinct in the stage III region of the dorsal caudate nucleus.

\section{MPTP-induced changes in midbrain GAP-43 mRNA expression}

There was a relatively high level of expression of GAP-43 mRNA in the substantia nigra of normal controls (Fig. 12A-C). Expression was particularly high in the ventral tier group of neurons. The dorsal tier, which extends caudally into the retrorubral area and medially into the lateral aspects of the ventral tegmental area (VTA), had moderate to low levels of mRNA expression (Fig. $12 B$ ). In particular, the VTA did not appear to be above background in expression of GAP-43 mRNA (Fig. 12C). In moderately and severely affected MPTP-treated animals there was a dramatic shift in the relative expression of GAP-43 (Fig. 12D-F). The most striking change was found in the VTA where there was an intense increase of GAP-43 mRNA expression (Fig. 12F). The dorsal tier group of neurons were also much more intensely labeled for GAP-43 mRNA (Fig. 12E) than controls. The expression of GAP-43 mRNA in the mildly affected case was not significantly different from normal controls. 

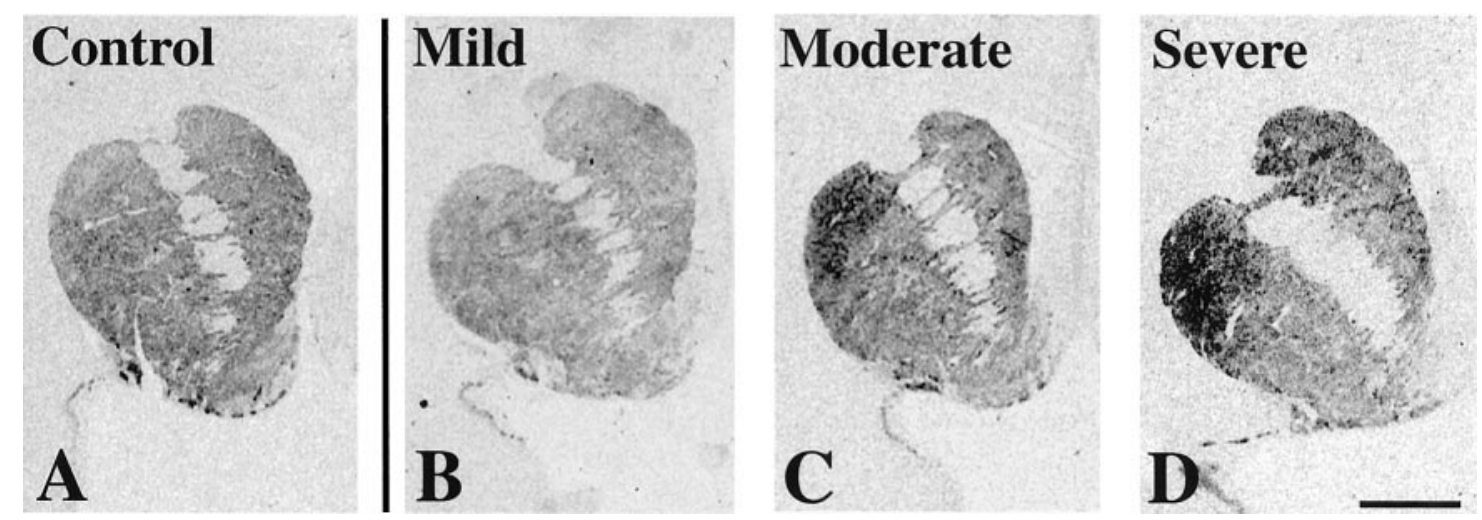

Figure 9. Film autoradiograms of $i n$ situ hybridization for PPE mRNA in the striatum. $A$, Control. $B$, Mild MPTP. $C$, Moderate MPTP. D, Severe MPTP. Note prominent increases in PPE mRNA expression in the dorsolateral striatum of moderate and severe MPTP-treated cases. Scale bar, $5 \mathrm{~mm}$.

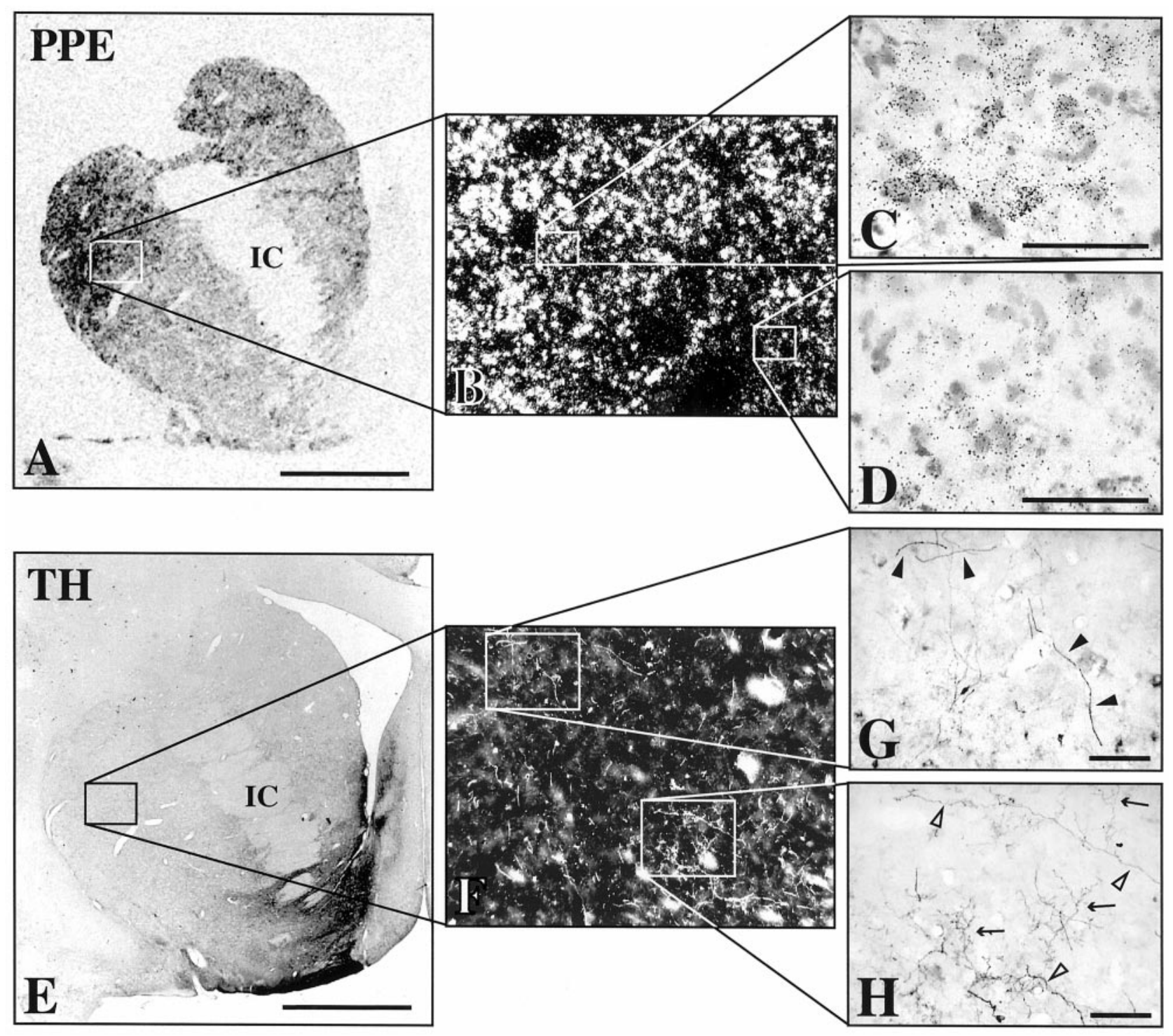

Figure 10. The correspondence of increased PPE mRNA expression to stage III TH fiber changes. $A-D$, In situ hybridization for PPE mRNA in the rostral striatum of severe MPTP-treated case. $E-H$, TH immunocytochemistry from an adjacent section. Note relatively normal PPE mRNA expression in stage II regions $(D, H)$ and increase in stage III regions $(C, G)$. Arrows, Type II TH fibers. Closed arrowheads, Type III TH fibers. Open arrowheads, Type IV TH fibers. $I C$, Internal capsule. Scale bars: $A, E, 5 \mathrm{~mm} ; C, D, G, H, 50 \mu \mathrm{m}$. 


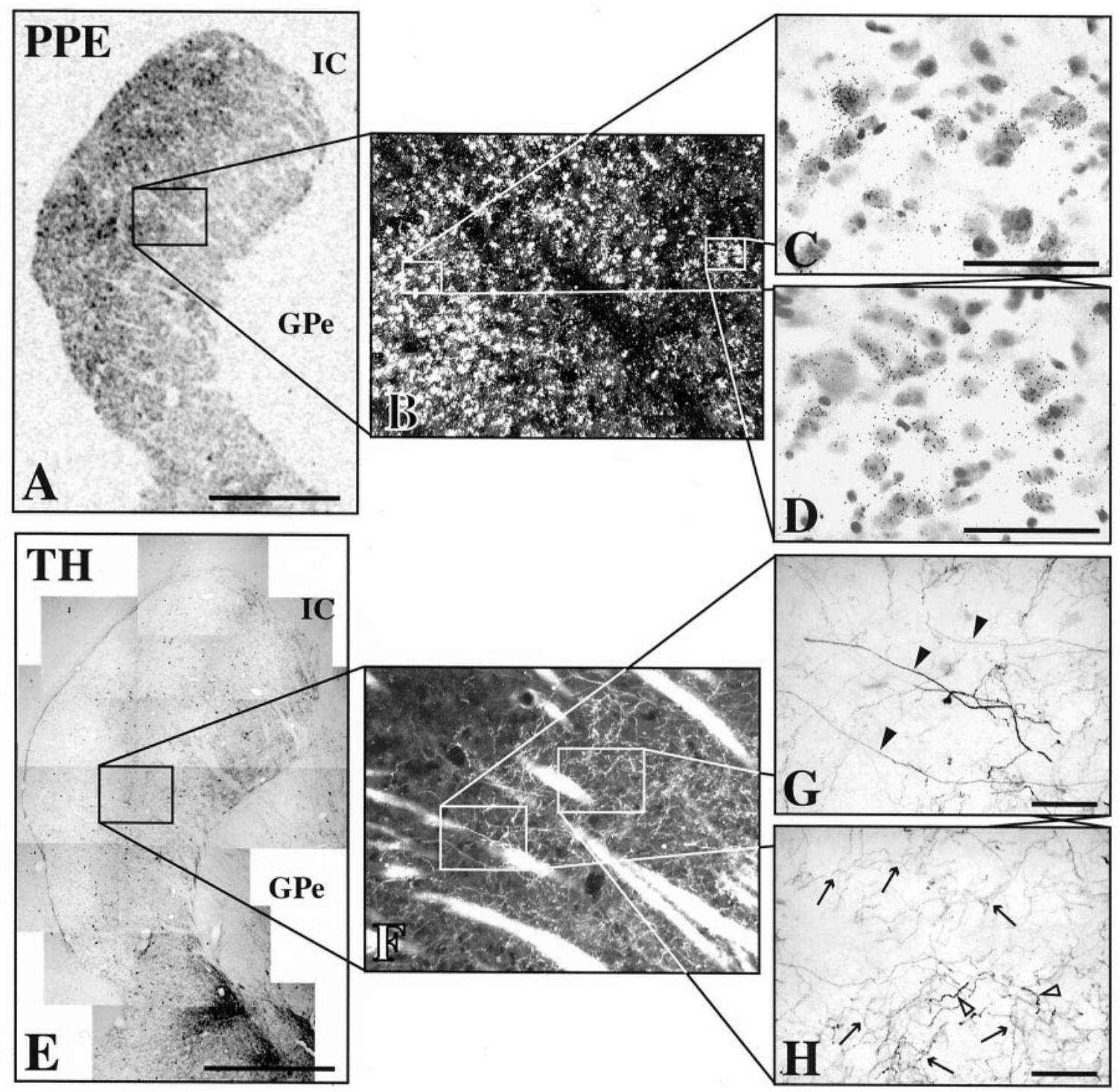

Figure 11. The correspondence of increased PPE mRNA expression to stage III TH fiber changes. $A-D$, In situ hybridization for PPE mRNA in the caudal striatum of moderate MPTP-treated case. $E-H$, TH immunocytochemistry from an adjacent section. Note relatively normal PPE mRNA expression in stage II regions $(D, H)$ and increase in stage III regions $(C, G)$. Arrows, Type II TH fibers. Closed arrowheads, Type III TH fibers. Open arrowheads, Type IV TH fibers. IC, Internal capsule; GPe, globus pallidus externa. Scale bars: $A, E, 5 \mathrm{~mm} ; C, D, G, H, 50 \mu \mathrm{m}$.

\section{DISCUSSION}

\section{Fiber types}

We found four different fibers types in the normal striatum that were distinguished by axonal diameter and morphology. While classified into different types, we cannot exclude that they may not be derived from separate cells. It is likely that collaterals from individual axons have different diameter size as has been demonstrated in other basal ganglia structures (Kita et al., 1983). Thus, for example, type three fibers may give rise to type two or type one fibers. Although the significance of different DA fiber diameters is unclear, it is likely related to conduction velocity (Gillespie and Stein, 1983; Minwegen and Friede, 1984; Sakai and Woody, 1988). A faster axonal conduction velocity is associated with fast firing or burst firing neurons (Jones et al., 1999). In the case of the SNpc cells, this can lead to increased release and higher extracellular DA concentrations (Gonon and Buda, 1985).
Indeed, after increases in burst firing activity, there is a saturability of dopamine reuptake (Chergui et al., 1994) leading to increases in extracellular DA and greater diffusion (Gonon, 1997). Thus, the larger DA axons diameters may be associated with faster conduction velocities, resulting in a mechanism to increase extracellular DA quickly in specific striatal regions. Alternatively, because DA release involves both tonic and phasic components (Grace, 1991), the different fiber types might be differentially associated with these two components.

After MPTP treatment, there are marked reductions in DA terminals with only a few remaining larger fibers (Willis and Donnan, 1987; Hess, 1989; Hess et al., 1990; Parent and Lavoie, 1993). In addition, there are reductions in NMDA receptormediated DA release (Andres et al., 1998). The loss of terminals and NMDA-mediated DA release places a greater dependence on phasic release of DA. Indeed, the remaining nigrostriatal 

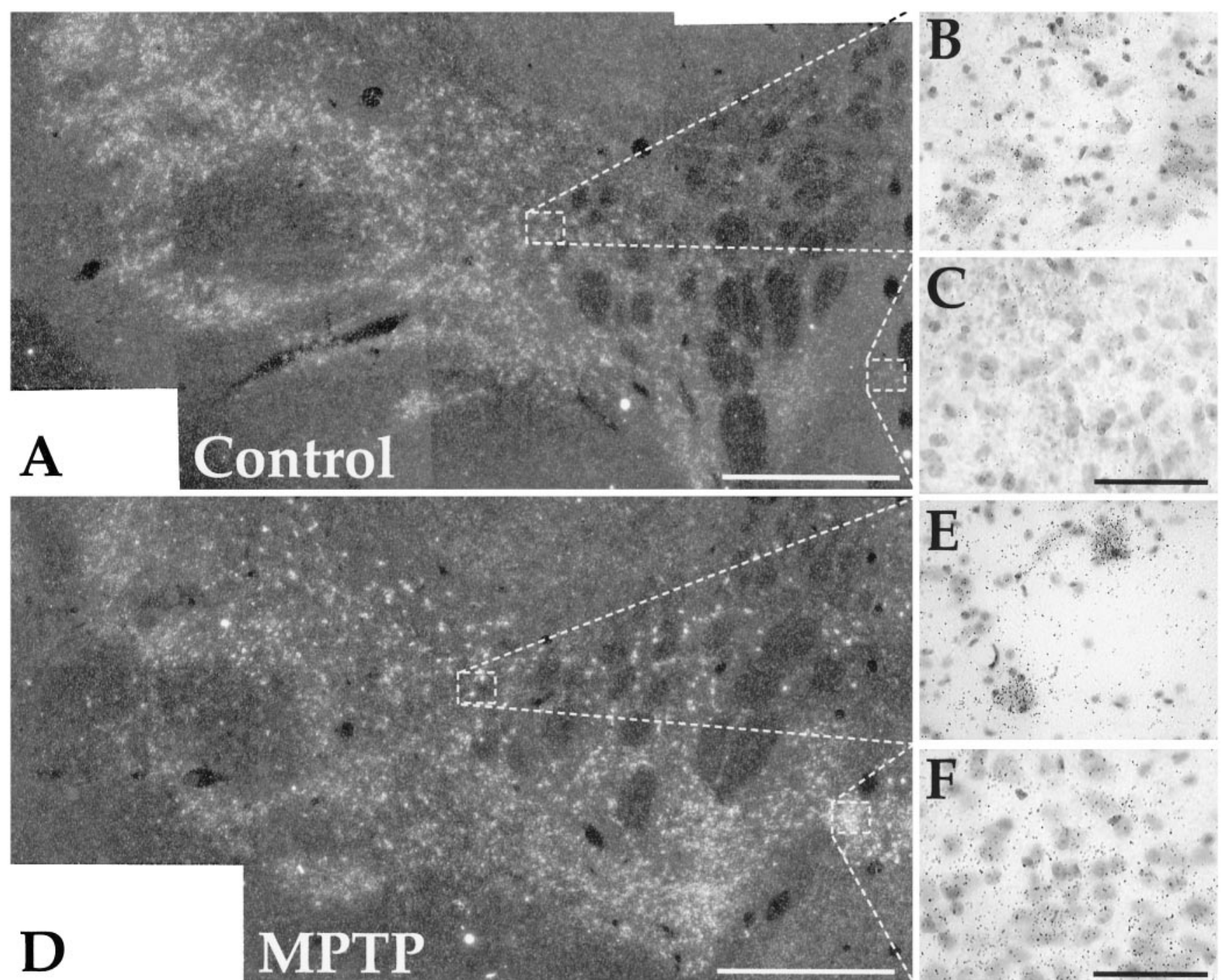

Figure 12. In situ hybridization for GAP-43 mRNA in the midbrain. $A-C$, Control. $D-F$, Moderate MPTP-treated case. Note GAP-43 mRNA expression is increased in the dorsal tier $(E)$ and ventral tegmental area $(F)$ after MPTP treatment. Scale bars: $A, D, 1 \mathrm{~mm} ; B, C, E, F, 50 \mu \mathrm{m}$.

neurons increase their firing rate or change to a burst pattern to increase DA release (Hollerman and Grace, 1990). This mechanism may allow an area of striatum relatively depleted of DA to maintain near normal extracellular DA levels. Thus, there is a compensatory advantage for DA cells to increase fiber diameter with a decrease in DA innervation.

\section{Fiber degeneration}

There was an overall progression of $\mathrm{TH}$ fiber loss, with the greatest loss dorsolaterally, less centrally, and least ventromedially. This pattern is consistent with the terminal projections of ventral and dorsal tier midbrain dopamine cells (Lynd-Balta and Haber, 1994b), which have different vulnerabilities to the toxic effects of MPTP (Schneider et al., 1987; Parent and Lavoie, 1993; Varastet et al., 1994). The distribution of silver deposits followed the course of the nigrostriatal pathway and were traced caudally to the SNpc cells. These cells had dense silver grain deposits, indicating that these cells were the source of the degeneration. Previous studies demonstrated that DA neurons lose their TH phenotype before degeneration (Kitt et al., 1986; Jackson-Lewis et al., 1995). Thus, our finding that there was little colocalization of TH-immunopositive fibers and silver grain deposits is not surprising. Of particular interest is the fact that the deposition of silver on cells, axons, and terminals was still present at 5 weeks after treatment with MPTP. This indicated that the degeneration process persists over several weeks and is consistent with human studies reporting active degeneration and dopaminergic terminal loss years after last exposure to MPTP (Vingerhoets et al., 1994; Langston et al., 1999).

\section{Compensatory sprouting}

Lack of colocalization of TH-positive fibers and silver grains is also supportive that the change in $\mathrm{TH}$ morphology is not caused by degeneration. Rather, the changes in morphology are likely to indicate regenerative compensation for the loss of striatal DA. Type III and IV TH fibers have similar morphologies and thicknesses to the coarse sprouting fibers found in fetal mesencephalic grafts $(0.3-1.0 \mu \mathrm{m}$ and $1.5-3.0 \mu \mathrm{m}$, respectively) (Dunnett et al., 1989; Taylor et al., 1990; Blanchard et al., 1996; Kordower et al., 1996). These fibers are also similar to the TH-immunoreactive fibers found during early development (Voorn et al., 1988; Song and Harlan, 1993). The mor- 
phological similarities of the large-diameter type III and IV fibers to developing DA fibers are particularly intriguing given evidence that neuroregenerative or repair processes can involve the reappearance of developmental processes, including increases in GAP-43, a developmentally regulated gene involved in sprouting (Tetzlaff et al., 1989; Benowitz and Perrone-Bizzozero, 1991; Benowitz and Routtenberg, 1997; Anderson et al., 1998). Of interest are recent studies showing that DA axons have the capability to continue to grow and sprout through adulthood (Benes and Todtenkopf, 1999).

The changes in mRNA for GAP-43 reported here further support the idea of compensatory sprouting in MPTP-treated animals. In our normal control animals and in the mildly affected animal, mRNA for GAP-43 is high in the ventral tier and relatively low in the dorsal tier. However, there was an increase in GAP-43 mRNA expression in the dorsal tier cells in the moderately and severely affected MPTP-treated animals. These animals exhibited stage II increases in thickness and branching, whereas the mildly affected animal did not. This increase in message suggests that the dorsal tier, which projects primarily to the ventral striatum (Lynd-Balta and Haber, 1994a), may be actively involved in sprouting (Aigner et al., 1995). Indeed, DA fibers in the ventromedial striatum have a greater regenerative or sprouting capacity (Onn et al., 1986; Fiandaca et al., 1988; Bankiewicz et al., 1991; Sheng et al., 1993; Hansen et al., 1995; Bjorklund and Stromberg, 1997). Increases in DA reuptake sites in the ventral striatum, despite severe dorsal striatal depletion, further support this (Gnanalingham et al., 1995). Other studies have demonstrated that DA axons can sprout, forming thick growth, cone-like structures after 6-OHDA lesions (Blanchard et al., 1996). Alternatively, or in addition, axons that remain in the dorsal striatum, but have not undergone degeneration may increase their innervation of the depleted region by branching or increasing in diameter.

The highly branched or bushy appearance of many of the $\mathrm{TH}$-immunoreactive fibers in stage II regions may be another means of compensating for the loss of DA by sprouting. During development, axonal branching is important in pathfinding, helping to localize targets (Davenport et al., 1999). By increasing the number of branches, remaining DA axons are distributed over a larger striatal area and are in a position to contact more striatal neurons. Many branching fibers were also covered with multiple small bushy branches, further increasing the potential for release of DA. Of particular interest was the fact that the highly branched fibers were only found in regions with a complete loss of only type I fibers (stage II regions).

\section{Regulation of PPE mRNA by striatal dopaminergic afferents}

Dopaminergic blockade or denervation results in a well described robust and reliable increase in striatal expression of PPE mRNA (Tang et al., 1983; Sivam et al., 1987; Normand et al., 1988; Gerfen et al., 1991; Gudehithlu et al., 1991; Asselin et al., 1994). The extent of increase in striatal PPE mRNA and protein expression has been shown to be directly related to the severity of Parkinsonian symptoms in MPTP-treated monkeys (Dacko and Schneider, 1991; Herrero et al., 1995). Furthermore, reversal of the elevation in PPE mRNA expression in MPTP-treated monkeys can be achieved with continuous treatment with receptor-specific DA agonists (Morissette et al., 1997, 1999). Thus, PPE mRNA expression may be an indirect indicator of dopamine function. Because the extent of branching and density of large-diameter TH fibers are likely to be involved in maintaining relatively normal dopamine function, particularly in stage II, these morphological changes may also help maintain relatively normal mRNA expression levels for PPE.

To test this, we compared the distribution of increased PPE mRNA expression with the distribution of the three stages in TH fiber loss. Significant increases in PPE mRNA expression corresponded only to regions with the loss of branched fibers (stage III regions). In contrast, regions containing numerous branched fibers (stage II regions) did not have an apparent change in PPE mRNA expression, despite severe overall loss of striatal TH immunoreactivity. This correspondence indicates that the appearance of highly branched or bushy fibers are likely contributors to the maintenance of normal PPE mRNA expression. It is also possible that other factors such as the glutamatergic corticostriatal input may play a role in PPE mRNA regulation (Romo et al., 1986; Leviel et al., 1990; Somers and Beckstead, 1990).

\section{Stages of dopamine loss and striatal compensation}

Multiple groups have described the necessity of severe depletions of DA in the dorsal striatum of $>90-95 \%$ to achieve a stable behavioral deficit (Elsworth et al., 1989; Robinson et al., 1990; Apicella et al., 1995). In MPTP-treated primates, behavioral recovery occurs most often using a low, chronic dose schedule of MPTP, which allows for compensatory mechanisms to evolve (Albanese et al., 1993; Gerlach and Riederer, 1996). Often with overall reductions in striatal DA content, extracellular DA levels are at or near normal levels when there is behavioral recovery (Zhang et al., 1988; Robinson et al., 1994). Relatively normal extracellular DA levels can be maintained by several mechanisms, including an increase in synthesis and a decrease in dopamine uptake (Zhang et al., 1988; Robinson et al., 1990; Zigmond et al., 1990; Cass et al., 1993). In addition to the above neurochemical changes as a means of compensating for dopamine depletion, behavioral recovery may also involve "sprouting" by the remaining DA fibers in the striatum (Fiandaca et al., 1988; Zhang et al., 1988; Sheng et al., 1993; Hansen et al., 1995).

We hypothesize that the three stages of $\mathrm{TH}$ fiber changes correspond to how the mesostriatal system responds to DA depletion. These three anatomic stages may correspond to the three physiological responses described by Robinson et al. (1994), which include: sparing of function ( $<80 \%$ striatal DA depletion), the recovery of function (80-95\% striatal DA depletion), and the loss of function ( $>95 \%$ striatal DA depletion). In stage I, there is a clear decrease in type I TH-positive fibers, but sufficient DA fibers remain to compensate neurochemically. At this level of DA loss, cells are able to decrease reuptake and/or increase synthesis to maintain sufficient extracellular DA. In stage II, the number and density of fibers become too low to compensate solely by neurochemical means, mRNA for GAP-43 increases in the midbrain and sprouting begins to occur in the striatum. In this situation, the combination of neurochemical means, along with sprouting and increased branching, results in relatively normal extracellular dopamine levels. However, as the degeneration becomes more severe (stage III), it is no longer possible to maintain extracellular dopamine levels. It is at this point that the mRNA for PPE is upregulated. 


\section{REFERENCES}

Abercrombie ED, Bonatz AE, Zigmond MJ (1990) Effects of L-DOPA on extracellular dopamine in striatum of normal and 6-hydroxydopamine-treated rats. Brain Res 525:36-44.

Aigner L, Arber S, Kapfhammer JP, Laux T, Schneider C, Botteri F, Brenner H-R, Caroni P (1995) Overexpression of the neural growthassociated protein GAP-43 induces nerve sprouting in the adult nervous system of transgenic mice. Cell 83:269-278.

Albanese A, Granata R, Gregori B, Piccardi MP, Colosimo C, Tonali P (1993) Chronic administration of 1-methyl-4-phenyl-1,2,3,6tetrahydropyridine to monkeys: behavioral, morphological and biochemical correlates. Neuroscience 55:823-832.

Anderson PN, Campbell G, Zhang Y, Lieberman AR (1998) Cellular and molecular correlates of the regeneration of adult mammalian CNS axons into peripheral nerve grafts. Prog Brain Res 117:211-232.

Andres ME, Gysling K, Bustos G (1998) Differential regulation of dopamine release by $N$-methyl-D-aspartate receptors in rat striatum after partial and extreme lesions of the nigro-striatal pathway. Brain Res 797:255-266.

Apicella P, Legallet E, Nieoullon A, Trouche E (1995) Quantitative behavioral study of the acute and long-term effects of two-stage bilateral 6-OHDA-induced lesions of the nigrostriatal dopaminergic system in monkeys. Behav Neurosci 109:329-341.

Asselin MC, Soghomonian JJ, Cote PY, Parent A (1994) Striatal changes in preproenkephalin mRNA levels in parkinsonian monkeys. NeuroReport 5:2137-2140.

Augood SJ, Emson PC, Mitchell IJ, Boyce S, Clarke CE, Crossman AR (1989) Cellular localisation of enkephalin gene expression in MPTPtreated cynomolgus monkeys. Brain Res Mol Brain Res 6:85-92.

Bankiewicz KS, Plunkett RJ, Jacobowitz DM, Kopin IJ, Oldfield EH (1991) Fetal nondopaminergic neural implants in parkinsonian primates. J Neurosurg 74:97-104.

Bendotti C, Servadio A, Samanin R (1991) Distribution of GAP-43 mRNA in the brain stem of adult rats as evidenced by in situ hybridization: localization within monoaminergic neurons. J Neurosci 11:600-607.

Benes FM, Todtenkopf MS (1999) Effect of age and neuroleptics on tyrosine hydroxylase-IR in sector CA2 of schizophrenic brain. NeuroReport 10:1-4.

Benowitz LI, Perrone-Bizzozero NI (1991) The relationship of GAP-43 to the development and plasticity of synaptic connections. Ann NY Acad Sci 627:58-74.

Benowitz LI, Routtenberg A (1997) GAP-43: an intrinsic determinant of neuronal development and plasticity. Trends Neurosci 20:84-91.

Bjorklund L, Stromberg I (1997) Dopaminergic innervation of striatal grafts placed into different sites of normal striatum: differences in the tyrosine hydroxylase immunoreactive growth pattern. Exp Brain Res 113:13-23.

Blanchard V, Anglade P, Dziewczapolski G, Savasta M, Agid Y, Raisman-Vozari R (1996) Dopaminergic sprouting in the rat striatum after partial lesion of the substantia nigra. Brain Res 709:319-325.

Boatell ML, Mahy N, Cardozo A, Ambrosio S, Tolosa E, Cruz-Sanchez FF (1992) Neuronal changes in the nigrostriatal pathway of 1-methyl4-phenylpyridine-treated mice. Methods Find Exp Clin Pharmacol 14:781-787.

Cass WA, Zahniser NR, Flach KA, Gerhardt GA (1993) Clearance of exogenous dopamine in rat dorsal striatum and nucleus accumbens: role of metabolism and effects of locally applied uptake inhibitors. J Neurochem 61:2269-2278.

Chergui K, Suaud-Chagny MF, Gonon F (1994) Nonlinear relationship between impulse flow, dopamine release and dopamine elimination in the rat brain in vivo. Neuroscience 62:641-645.

Comb M, Seeburg PH, Adelman J, Eiden L, Herbert E (1982) Primary structure of the human Met-and Leu-enkephalin precursor and its mRNA. Nature 295:663-666.

Dacko S, Schneider JS (1991) Met-enkephalin immunoreactivity in the basal ganglia in symptomatic and asymptomatic MPTP-exposed monkeys: correlation with degree of parkinsonian symptoms. Neurosci Lett 127:49-52.

Dani JW, Armstrong DM, Benowitz LI (1991) Mapping the development of the rat brain by GAP-43 immunocytochemistry. Neuroscience 40:277-287.

Davenport RW, Thies E, Cohen ML (1999) Neuronal growth cone collapse triggers lateral extensions along trailing axons. Nat Neurosci [Erratum (1999) 2:485] 2:254-259.
De Olmos JS, Beltramino CA, and De Olmos De Lorenzo S (1994) Use of an amino-cupric-silver technique for the detection of early and semiacute neuronal degeneration caused by neurotoxicants, hypoxia, and physical trauma. Neurotoxicol Teratol 16:545-561.

Dunnett SB, Rogers DC, Richards SJ (1989) Nigrostriatal reconstruction after 6-OHDA lesions in rats: combination of dopamine-rich nigral grafts and nigrostriatal "bridge" grafts. Exp Brain Res 75:523-535.

Elsworth JD, Deutch AY, Redmond Jr DE, Taylor JR, Sladek Jr JR, Roth RH (1989) Symptomatic and asymptomatic 1-methyl-4-phenyl-1,2,3,6tetrahydropyridine-treated primates: biochemical changes in striatal regions. Neuroscience 33:323-331.

Fiandaca MS, Kordower JH, Hansen JT, Jiao SS, Gash DM (1988) Adrenal medullary autografts into the basal ganglia of Cebus monkeys: injury-induced regeneration. Exp Neurol 102:76-91.

Gerfen CR, McGinty JF, Young WS (1991) Dopamine differentially regulates dynorphin, substance $\mathrm{P}$, and enkephalin expression in striatal neurons: in situ hybridization histochemical analysis. J Neurosci 11:1016-1031.

Gerlach M, Riederer P (1996) Animal models of Parkinson's disease: an empirical comparison with the phenomenology of the disease in man. J Neural Transm (Budapest) 103:987-1041.

Gillespie MJ, Stein RB (1983) The relationship between axon diameter, myelin thickness and conduction velocity during atrophy of mammalian peripheral nerves. Brain Res 259:41-56.

Gnanalingham KK, Milkowski NA, Smith LA, Hunter AJ, Jenner P, Marsden CD (1995) Short- and long-term changes in striatal and extrastriatal dopamine uptake sites in the MPTP-treated common marmoset. Eur J Pharmacol 277:235-241.

Gonon F (1997) Prolonged and extrasynaptic excitatory action of dopamine mediated by $\mathrm{D} 1$ receptors in the rat striatum in vivo. J Neurosci 17:5972-5978.

Gonon FG, Buda MJ (1985) Regulation of dopamine release by impulse flow and by autoreceptors as studied by in vivo voltammetry in the rat striatum. Neuroscience 14:765-774.

Grace AA (1991) Phasic versus tonic dopamine release and the modulation of dopamine system responsivity: a hypothesis for the etiology of schizophrenia. Neuroscience 41:1-24.

Gudehithlu KP, Duchemin AM, Tejwani GA, Neff NH, Hadjiconstantinou M (1991) Preproenkephalin mRNA and methionineenkephalin increase in mouse striatum after 1-methyl-4-phenyl-1,2,3,6tetrahydropyridine treatment. J Neurochem 56:1043-1048.

Hansen JT, Sakai K, Greenamyre JT, Moran S (1995) Sprouting of dopaminergic fibers from spared mesencephalic dopamine neurons in the unilateral partial lesioned rat. Brain Res 670:197-204.

Herrero MT, Augood SJ, Hirsch EC, Javoy-Agid F, Luquin MR, Agid Y, Obeso JA, Emson PC (1995) Effects of L-DOPA on preproenkephalin and preprotachykinin gene expression in the MPTP-treated monkey striatum. Neuroscience 68:1189-1198.

Hess A (1989) Neuropathological changes in the caudate nucleus elicited by MPTP and their prevention by monoamine oxidase inhibition. Brain Res 499:393-396.

Hess A, Desiderio C, McAuliffe WG (1990) Acute neuropathological changes in the caudate nucleus caused by MPTP and methamphetamine: immunohistochemical studies. J Neurocytol 19:338-342.

Hollerman JR, Grace AA (1990) The effects of dopamine-depleting brain lesions on the electrophysiological activity of rat substantia nigra dopamine neurons. Brain Res 533:203-212.

Jackson-Lewis V, Jakowec M, Burke RE, Przedborski S (1995) Time course and morphology of dopaminergic neuronal death caused by the neurotoxin 1-methyl-4-phenyl-1,2,3,6-tetrahydropyridine. Neurodegeneration 4:257-269.

Jones GA, Norris SK, Henderson Z (1999) Conduction velocities and membrane properties of different classes of rat septohippocampal neurons recorded in vitro. J Physiol (Lond) 517:867-877.

Kita H, Chang HT, Kitai ST (1983) The morphology of intracellularly labeled rat subthalamic neurons: a light microscopic analysis. J Comp Neurol 215:245-257.

Kitt CA, Cork LC, Eidelberg F, Joh TH, Price DL (1986) Injury of nigral neurons exposed to 1-methyl-4-phenyl-1,2,3,6-tetrahydropyridine: a tyrosine hydroxylase immunocytochemical study in monkey. Neuroscience 17:1089-1103.

Kordower JH, Rosenstein JM, Collier TJ, Burke MA, Chen E-Y, Li JM, Martel L, Levey AE, Mufson EJ, Freeman TB, Olanow CW (1996) Functional fetal nigral grafts in a patient with Parkinson's disease: 
chemoanatomic, ultrastructural, and metabolic studies. J Comp Neurol 370:203-230.

Kowalski C, Giraud P (1993) Dopamine decreases striatal enkephalin turnover and proenkephalin messenger RNA abundance via D2 receptor activation in primary striatal cell cultures. Neuroscience 53:665-672.

Langston JW, Forno LS, Rebert CS, Irwin I (1984) Selective nigral toxicity after systemic administration of 1-methyl-4-phenyl-1,2,5,6tetrahydropyridine (MPTP) in the squirrel monkey. Brain Res 292:390-394.

Langston JW, Forno LS, Tetrud J, Reeves AG, Kaplan JA, Karluk D (1999) Evidence of active nerve cell degeneration in the substantia nigra of humans years after 1-methyl-4-phenyl-1,2,3,6-tetrahydropyridine exposure. Ann Neurol 46:598-605.

Leviel V, Gobert A, Buibert B (1990) The glutamate-mediated release of dopamine in the rat striatum: further characterization of the dual excitatory-inhibitory function. Neuroscience 39:305-312.

Li SJ, Jing HK, Hudson PM, Owyang V, Nanry K, Tilson HA, Hong JS (1990) Influence of nigrostriatal dopaminergic tone on the biosynthesis of dynorphin and enkephaline in rat striatum. Mol Brain Res $8: 219-225$.

Lu W, Haber SN (1992) In situ hybridization histochemistry: A new method for processing material stored for several years. Brain Res 578:155-160.

Lynd-Balta E, Haber SN (1994a) The organization of midbrain projections to the striatum in the primate: sensorimotor-related striatum versus ventral striatum. Neuroscience 59:625-640.

Lynd-Balta E, Haber SN (1994b) Primate striatonigral projections: a comparison of the sensorimotor-related striatum and the ventral striatum. J Comp Neurol 343:1-17.

Minwegen P, Friede RL (1984) Conduction velocity varies with osmotically induced changes of the area of the axon's profile. Brain Res 297:105-113.

Mocchetti I, Naranjo JR, Costa E (1987) Regulation of striatal enkephalin turnover in rats receiving antagonists of specific dopamine receptor subtypes. J Pharmacol Exp Ther 241:1120-1124.

Morissette M, Goulet M, Soghomonian JJ, Blanchet PJ, Calon F, Bedard PJ, Di Paolo T (1997) Preproenkephalin mRNA expression in the caudate-putamen of MPTP monkeys after chronic treatment with the D2 agonist U91356A in continuous or intermittent mode of administration: comparison with L-DOPA therapy. Brain Res Mol Brain Res 49:55-62.

Morissette M, Grondin R, Goulet M, Bedard PJ, Di Paolo T (1999) Differential regulation of striatal preproenkephalin and preprotachykinin mRNA levels in MPTP-lesioned monkeys chronically treated with dopamine D1 or D2 receptor agonists. J Neurochem 72:682-692.

Nisenbaum L, Kitai ST, Gerfen CR (1994) Dopaminergic and muscarinic regulation of striatal enkephalin and substance $\mathrm{P}$ messenger RNAs following striatal dopamine denervation: effects of systemic and central administration of quinpirole and scopolamine. Neuroscience 63:435-449.

Normand E, Popovici T, Onteniente B, Fellmann D, Piatier-Tonneauk D, Auffray C, Block B (1988) Dopaminergic neurons of the substantia nigra modulate preproenkephalin A gene expression in rat striatal neurons. Brain Res 439:39-46.

Onn S-P, Berger TW, Stricker EM, Zigmond MJ (1986) Effects of intraventricular 6-hydroxydopamine on the dopaminergic innervation of striatum: Histochemical and neurochemical analysis. Brain Res 376:8-19.

Parent A, Lavoie B (1993) The heterogeneity of the mesostriatal dopaminergic system as revealed in normal and Parkinsonian monkeys. Adv Neurol 60:25-20.

Parent A, Asselin MC, Cote PY (1996) Dopaminergic regulation of peptide gene expression in the striatum of normal and parkinsonian monkeys. Adv Neurol 69:73-77.

Robinson TE, Castaneda E, Whishaw IQ (1990) Compensatory changes in striatal dopamine neurons following recovery from injury induced by 6-OHDA or methamphetamine: a review of evidence from microdialysis studies. Can J Psychol 44:253-275.
Robinson TE, Mocsary Z, Camp DM, Whishaw IQ (1994) Time course to recovery of extracellular dopamine following partial damage to the nigrostriatal dopamine system. J Neurosci 14:2687-2696.

Romo R, Cheramy A, Godeheu G, Glowinski J (1986) In vivo presynaptic control of dopamine release in the cat caudate nucleus III. Further evidence for the implication of corticostriatal glutamatergic neurons. Neuroscience 19:1091-1099.

Sakai H, Woody CD (1988) Relationships between axonal diameter, soma size, and axonal conduction velocity of HRP-filled, pyramidal tract cells of awake cats. Brain Res 460:1-7.

Schneider JS, Yuwiler A, Markham CH (1987) Selective loss of subpopulations of ventral mesencephalic dopaminergic neurons in the monkey following exposure to MPTP. Brain Res 411:144-150.

Sheng JG, McShane LM, Plunkett RJ, Cummins AC, Oldfield EH, Kopin IJ, Palmatier MA (1993) Dopaminergic neuronal sprouting and behavioral recovery in hemi-parkinsonian rats after implantation of amnion cells. Exp Neurol 123:192-203.

Sivam SP, Breese GR, Krause JE, Napier TC, Mueller RA, Hong J-S (1987) Neonatal and adult 6-hydroxydopamine-induced lesions differentially alter tachykinin and enkephalin gene expression. J Neurochem 49:1623-1633.

Somers DL, Beckstead RM (1990) Striatal preprotachykinin and preproenkephalin mRNA levels and the levels of nigral substance $\mathrm{P}$ and pallidal Met5-enkephalin depend on corticostriatal axons that use the excitatory amino acid neurotransmitters aspartate and glutamate: quantitative radioimmunocytochemical and in situ hybridization evidence. Mol Brain Res 8:143-158.

Song DD, Harlan RE (1993) Ontogeny of the proenkephalin system in the rat corpus striatum: its relationship to dopaminergic innervation and transient compartmental expression. Neuroscience 52:883-909.

Song DD, Switzer IIIRC, Fudge JL, Haber SN (1999) Striatal consequences of partial dopamine lesion: changes in dopaminergic fiber morphology, degeneration, and preproenkephalin (PPE) expression. Soc Neurosci Abstr 25:1653.

Tang F, Costa E, Schwartz JP (1983) Increase of proenkephalin mRNA and enkephalin content of rat striatum after daily injection of haloperidol for 2 to 3 weeks. Proc Natl Acad Sci USA 80:3841-3844.

Taylor JR, Elsworth JD, Roth RH, Collier TJ, Sladek Jr JR, Redmond DE Jr (1990) Improvements in MPTP-induced object retrieval deficits and behavioral deficits after fetal nigral grafting in monkeys. Prog Brain Res 82:543-559.

Tetzlaff W, Zwiers H, Lederis K, Cassar L, Bisby MA (1989) Axonal transport and localization of B-50/GAP-43-like immunoreactivity in regenerating sciatic and facial nerves of the rat. J Neurosci 9:1303-1313.

Varastet M, Riche D, Maziere M, Hantraye P (1994) Chronic MPTP treatment reproduces in baboons the differential vulnerability of mesencephalic dopaminergic neurons observed in Parkinson's disease. Neuroscience 63:47-56.

Vingerhoets FJ, Snow BJ, Tetrud JW, Langston JW, Schulzer M, Calne DB (1994) Positron emission tomographic evidence for progression of human MPTP-induced dopaminergic lesions. Ann Neurol 36:765-770.

Voorn P, Kalsbeek A, Jorritsma-Byham B, Groenewegen HJ (1988) The pre- and postnatal development of the dopaminergic cell groups in the ventral mesencephalon and the dopaminergic innervation of the striatum of the rat. Neuroscience 25:857-887.

Willis GL, Donnan GA (1987) Histochemical, biochemical and behavioural consequences of MPTP treatment in C-57 black mice. Brain Res 402:269-274.

Zhang WQ, Tilson HA, Nanry KP, Hudson PM, Hong JS, Stachowiak MK (1988) Increased dopamine release from striata of rats after unilateral nigrostriatal bundle damage. Brain Res 461:335-342.

Zigmond MJ, Berger TW, Grace AA, Stricker EM (1989) Compensatory responses to nigrostriatal bundle injury. Studies with 6-hydroxydopamine in an animal model of parkinsonism. Mol Chem Neuropathol 10:185-200.

Zigmond MJ, Abercrombie ED, Berger TW, Grace AA, Stricker EM (1990) Compensations after lesions of central dopaminergic neurons: some clinical and basic implications. Trends Neurosci 13:290-296. 